\title{
Synthesis of Chromane Derivatives by Palladium-Catalyzed Intramolecular Allylation of Aldehydes with Allylic Acetates or Chlorides Using Indium and Indium(III) Chloride
}

\author{
Van Cuong Nguyen, Yong-Tae Kim, Yeon-Kwon Yu, and Han-Young Kang* \\ Department of Chemistry and Institute of Basic Sciences, Chungbuk National University, Cheongju, Chungbuk 361-763, Korea \\ *E-mail:hykang@chungbuk.ac.kr \\ Received February 1, 2005
}

Key Words : Chromane, Indium, Intramolecular allylation reactions, Palladium, Transmetallation

Since chromanes are found in many natural products, efficient construction of this ring structure has attracted much attention. ${ }^{1}$ We have investigated indium-mediated intramolecular allylation and allenylation to carbonyl groups as well as imines and proved that these methods are efficient for constructing chromane ring structures. ${ }^{2-4}$ Recently, Araki and co-workers reported the transmetallation of $\pi$-allylpalladium(II) by an indium(I) salt and showed that allylation to carbonyl groups could be achieved by the resulting organoindium species. ${ }^{5}$ This process appears to involve a $\pi$ allylpalladium(II) species which was, then, transmetallated with an indium salt. As a result, an allylindium reagent was generated, which is believed to be the active organometallic species to undergo allylation. Also, a very similar allylation using $\mathrm{In}, \mathrm{InCl}_{3}$, and catalytic $\mathrm{Pd}(0)$ to carbonyl groups was also reported by Kim and co-workers. ${ }^{6}$ The actual active species involved for transmetallation in this process was also believed to be $\mathrm{InCl}$, which was formed by the reaction of indium and indium(III) chloride. Interestingly, other metal chloride salts with higher reduction potential than $\operatorname{In}(\mathrm{I})$ can be utilized in the allylation reactions. Thus, $\mathrm{SnCl}_{4}, \mathrm{FeCl}_{3}$, or $\mathrm{CuCl}$ paired with indium metal in the presence of $\mathrm{Pd}(0)$ was successfully employed in the allylation with various allylic compounds. More recently, Araki and co-workers reported preparation of allylic indium from allylic alcohols via $\pi$ allylnickel with InI. ${ }^{7}$ Allylindiums generated by abovementioned reductive transmetallation of $\pi$-allylpalladium(II) complexes were also used in allyl cross-coupling reactions. ${ }^{8}$

Because these methods seem to be efficient in allylation in intermolecular fashion, it is natural to consider possibility of applying these to intramolecular allylations. In connection with our continuing efforts to develop more efficient methods to synthesize chromane and chromane-related ring structures using organoindium species, ${ }^{9}$ we decided to investigate the allylation involving $\mathrm{In}, \mathrm{InCl}_{3}$, and $\operatorname{Pd}(0)$ species to prepare chromane derivatives.

Here we wish to disclose the results of our investigation on acquiring chromane and the related structures via an organoindium species generated by the transmetallation of $\pi$-allylpalladium(II) according to the allylation method reported by Kim and co-workers. ${ }^{6}$ First, we have focused our investigation on the construction of chromanes which possess 6-membered rings by the intramolecular allylation under the conditions involving In and $\mathrm{InCl}_{3}$ in the presence of $\mathrm{Pd}\left(\mathrm{PPh}_{3}\right)_{4}$ (Eq. 1).<smiles>CC(=O)OCC#CCOc1ccccc1C=O</smiles><smiles>C=CC1=C(O)c2ccccc2OC1</smiles>

Since Kim and co-workers reported that the allylation in intermolecular fashion was efficiently achieved only in aqueous media, our intramolecular allylation was also performed in $\mathrm{THF}-\mathrm{H}_{2} \mathrm{O}[1: 1(v / v)]$. The results of the intramolecular allylation to form chromanes are summarized in Table 1. Generally, all the cyclizations to form six-

Table 1. Preparation of chromane derivatives by allylation ${ }^{a}$
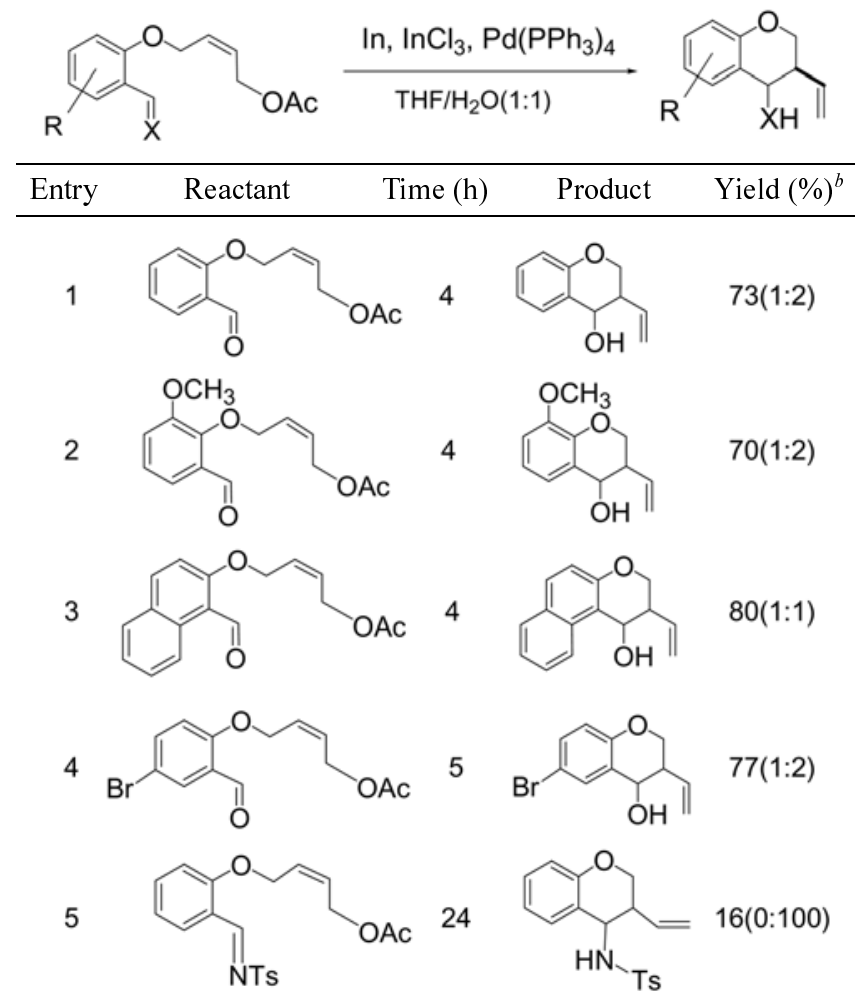

${ }^{a}$ Substrate $: \operatorname{In}: \mathrm{InCl}_{3}: \operatorname{Pd}\left(\mathrm{PPh}_{3}\right)_{4}=1: 2: 0.5: 0.05 .{ }^{b}$ Ratios in parenthesis indicate isomeric ratios (trans/cis). 
Table 2. Preparation of chromane derivatives by allylation ${ }^{a}$<smiles>C=CC1COc2ccccc2CC1OC(=O)COCC(=C)COC(=O)c1ccccc1OCC(=C)COC(=O)c1ccccc1C=O</smiles>

${ }^{a}$ Substrate $: \operatorname{In}: \mathrm{InCl}_{3}: \mathrm{Pd}\left(\mathrm{PPh}_{3}\right)_{4}=1: 2: 0.5: 0.05 .{ }^{b}$ Isomeric ratio.

membered rings proceeded smoothly in good yields. This is consistent with the results obtained previously in indiummediated intramolecular allylations of allylic bromides to carbonyl groups. ${ }^{2,3}$ Unfortunately, the ratios of the stereoisomers (cis-trans ratio) were not improved. Similar ratios to those obtained from indium-mediated allylation with allyl bromides previously reported might indicate the identical nature of the organoindium intermediates involved in both allylation methods. This $\mathrm{Pd}(0)-\mathrm{In}-\mathrm{InCl}_{3}$ method was also applied to the $\mathrm{C}=\mathrm{N}$ bond (entry 5). In this case, although only a single isomer (that is, cis isomer as previously observed in the case of the indium-mediated allylation ${ }^{4}$ ) was obtained, the yield was not satisfactory. Usually allylations to $\mathrm{C}=\mathrm{O}$ bonds were completed in $4-5 \mathrm{~h}$, although $24 \mathrm{~h}$ was required for the allylation to $\mathrm{C}=\mathrm{N}$.

Since the intramolecular allylation to form chromane rings was effectively achieved, we decided to investigate whether this allylation could be successfully extended to form larger rings. The results of investigation along this line of research are shown in Table 2. Although in one case (entry 1), the intramolecular allylations proceeded in decent yield $(62 \%$, mixture of cis/trans isomers: The stereochemistry of the major and the minor isomer was not identified.), usually the yields of the allylations to form 7- or 8-membered oxacycles turned out to be lower (46-56\%, entries 3, 4, and 7). Intramolecular allylation could be also successfully achieved in the case of forming lactones (entries 2, 5, and 6). Allylic chlorides instead of allylic acetates could be successfully used in this allylation (entries 4 and 6). Allenylation in forming 6-membered and larger rings was tested with $\mathbf{1}$ and 2 , but no cyclization was observed. ${ }^{10}$

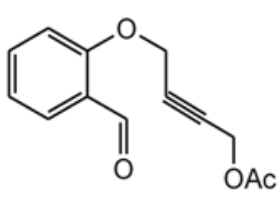

1

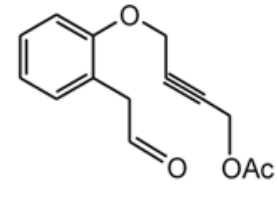

2
Acknowledgements. This work was supported by Chungbuk National University Grant in 2004.

\section{References}

1. (a) Tocopherol A: Solladie, G.; Moine, G. J. Am. Chem. Soc. 1984, 106, 6097. (b) Calanolide A: Chenera, B.; West, M. L.; Finkelstein, J. A.; Dreyer, G. B. J. Org. Chem. 1993, 58, 5605. (b) Rao, A. V. R.; Gaitonde, A. S.; Prakash, K. R. C.; Rao, S. P. Tetrahedron Letters 1994, 35, 6347. (c) Partial estrogens: Bury, P. S.; Christiansen, L. B.; Jacobsen, P.; Jørgensen, A. S.; Kanstrup, A.; Nærum, L.; Bain, S.; Fledelius, C.; Gissel, B.; Hansen, B. S.; Korsgaard, N.; Thorpe, S. M.; Wasserman, K. Bioorg. Med. Chem. 2002, 10, 125.

2. Kang, H.-Y.; Kim, Y.-T.; Yu, Y.-K.; Cha, J. H.; Cho, Y. S.; Koh, H. Y. Synlett 2004, 45.

3. Cha, J. H.; Cho, Y. S.; Koh, H. Y.; Lee, E.; Kim, Y.-T.; Yang, H.H.; Kang, H.-Y. Bull. Korean Chem. Soc. 2004, 25, 1123.

4. Kang, H.-Y.; Yu, Y.-K. Bull. Korean Chem. Soc. 2004, 25, 1627.

5. Araki, S.; Kamei, T.; Hirachita, T.; Yamamura, H.; Kawai, M. Org. Lett. 2000, 2, 847.

6. Jang, T.-S.; Keum, G.; Kang, S.-B.; Chung, B.-Y.; Kim, Y. Synthesis 2003, 5, 775.

7. Hirashita, T.; Kambe, S.; Tsuki, H.; Omori, H.; Araki, S. J. Org. Chem. 2004, 69, 5054.

8. Lee, P. H.; Seomoon, D.; Lee, K.; Kim, S.; Kim, H.; Kim, H.; Shim, E.; Lee, M.; Lee, S.; Kim, M.; Sridbar, M. Adv. Synth. Catal. 2004, 346, 1641.

9. (a) Shin, J. A.; Choi, K. I.; Pae, A. N.; Koh, H. Y.; Kang, H.-Y.; Cho, Y. S. J. Chem. Soc. Perkin Trans. 1 2001, 946. (b) Shin, J. A.; Cha, J. W.; Pae, A. N.; Choi, K. I.; Koh, H. Y.; Kang, H.-Y.; Cho, Y. S. Tetrahedron Lett. 2001, 42, 5489.

10. Typical procedure: Preparation of 3-vinylchroman-4-ol (Table 1 , entry 1). To a mixture of indium $(23.0 \mathrm{mg}, 0.20 \mathrm{mmol}), \mathrm{InCl}_{3}$ (11.1 $\mathrm{mg}, 0.05 \mathrm{mmol})$, and $\mathrm{Pd}\left(\mathrm{PPh}_{3}\right)_{4}(5.8 \mathrm{mg}, 0.005 \mathrm{mmol})$ was added 2-((Z)-4-acetoxybut-2-enoxy)benzaldehyde $(23.4 \mathrm{mg}, 0.10$ $\mathrm{mmol})$ in $\mathrm{THF} / \mathrm{H}_{2} \mathrm{O}(2 \mathrm{~mL}, v / v=1: 1)$ at room temperature. The resulting mixture was stirred for $4 \mathrm{~h}$ at room temperature. After the starting aldehyde was consumed, the reaction mixture was quenched with $\mathrm{HCl}(1 \mathrm{~N}, 0.5 \mathrm{~mL})$ and extracted with ether $(10 \mathrm{~mL}$ $\times 3$ ). The organic layer was washed with brine and dried over anhydrous $\mathrm{MgSO}_{4}$. The solvent was removed and residue was purified by flash chromatograph (hexane : ethyl acetate $=3: 1$ ) to afford the desired product as a mixture of trans and cis compound (trans: cis $=1: 2)(12.9 \mathrm{mg}, 73 \%)$. 